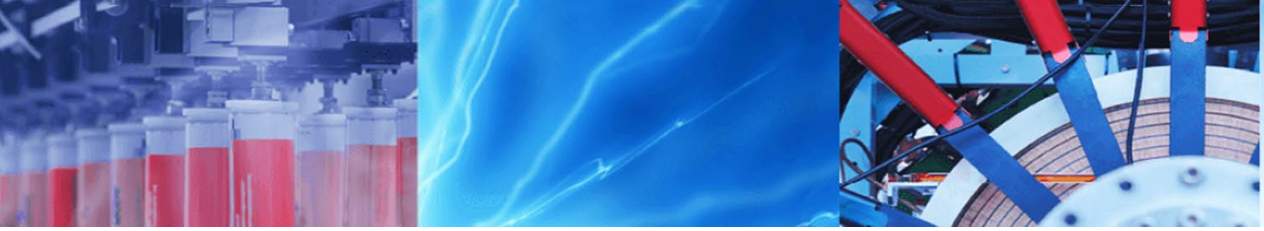

Research Article

\title{
Geophysical exploration of titanomagnetite ore deposits by geomagnetic and geoelectric methods
}

\author{
Salah Abdel Wahab Mousa ${ }^{1}$ - Sami Hamed Abdel Nabi ${ }^{1}$. Sultan Awad Sultan Araffa ${ }^{2}$ Salah Ahmed Mansour ${ }^{3}$. \\ Mohamed AbdElsabour Ibrahim AI Deep ${ }^{2}$ (1)
}

Received: 15 November 2019 / Accepted: 6 February 2020 / Published online: 18 February 2020

(c) Springer Nature Switzerland AG 2020

\begin{abstract}
Geophysical techniques, such as magnetic and geoelectric ones, are useful for ore deposit exploration, represented by titanomagnetite. Titanomagnetite is a mineral composed of oxides of titanium and iron. Forty-seven magnetic profiles have been measured using two proton magnetometers to cover the study area with a direction perpendicular to the ore outcrops. The qualitative interpretation of magnetic data indicates elongated highly magnetized anomalies extending northeast to southwest. The quantitative interpretation of magnetic data was carried out using 2D magnetic inversion. The results of the magnetic interpretation indicated ore deposits at $<10 \mathrm{~m}$ depth in the area with highly magnetic anomalies, and the magnetic anomalies related to the titanomagnetite ore bodies have a tabular form with thickness ranging from 7 to $100 \mathrm{~m}$. Seven vertical electrical soundings were carried out along selected sites according to the geologic map and field observation for the geologic features of the ore bodies in the study area. The results of resistivity inversions indicated that there are many conductive bodies, which have resistivity values $<100 \Omega \mathrm{m}$. Three electric resistivity tomography lines are made trending east-west perpendicular to the direction of exposed ore in the area. The profiles were processed using the finite element algorithm available in the Res2dinv program, and the generated models delineate the shape and orientation of the supposed ore.
\end{abstract}

Keywords Mineral exploration · Titanomagnetite · Magnetic survey · Vertical electrical sounding · 2D inversion

\section{Introduction}

Mineral extraction is a very precise operation, so, in the exploration methods, the key is to improve the accuracy of the location and size of the mineral detected. In this research, geophysical prospecting techniques give a primary idea about the presence of metallic deposits. Titanomagnetite is a mineral of the complex oxide class. An intermediate member of the isomorphic series of solid solutions, its comprises magnetite $\left(\mathrm{Fe}_{2} \mathrm{O}_{4}\right)$, ulvospinel ( $\mathrm{Mg}$ $\left.\mathrm{Fe}_{2} \mathrm{TiO}_{4}\right)$, and magnesian ulvospinel $\left(\mathrm{Mg}_{3} \mathrm{TiO}_{4}\right)$. From field observations, we can describe that ore takes the form of thin parallel layers, oriented vertically and surrounded by the gabbroic host rock. Depending on the physical properties of minerals and their associated rocks, we use three main geophysical approaches: resistivity, induced polarization, and the magnetic method. Each measures certain physical properties, such as electric resistivity, electric rechargeablity, and magnetic susceptibility, in a homogeneous material. All the methods should agree with the expected earth model. The high magnetic susceptibility of magnetite minerals gives an advantage to the magnetic method. These minerals have high magnetic susceptibility ranging from 1 to $60 \mathrm{SI}$ units according to Clark and

\footnotetext{
$\triangle$ Mohamed AbdElsabour Ibrahim Al Deep, mohamed-abdelsabour@outlook.com | ${ }^{1}$ Faculty of Science, Ain Shams University, Cairo, Egypt. ${ }^{2}$ National Research Institute of Astronomy and Geophysics, Helwan, Cairo, Egypt. ${ }^{3}$ Egyptian General Mineral Resource Authority (EMRA), Abbassia, Cairo, Egypt.
} 
Emerson [1] and can generate a strong induced magnetic field. However, the electric resistivity method is applied because of the high conductivity of titanomagnetite and the associated minerals. Many previous studies have assessed the occurrence and distribution of titanomagnetite ore in the area including geochemical and geologic studies by Takla [2] and Takla et al. [3] and a chronologic study by Zimmer et al. [4]. The magnetic and conductance properties of titanomagnetite were studied by Brabers [5] and Radhakrishnamurty et al. [6].

Sultan et al. [7] used the magnetic method to detect gold and its associated metallic sources in Marsa Alam, Egypt, as well as its depth. Anaïs et al. [8] conducted an interpretation of the mineralization regions from highdensity aeromagnetic data in the Jameson Land Basin, central East Greenland, depending on the high contrast in magnetic susceptibility between basement rocks and structures filled with minerals. Heritiana et al. [9] used a combination of geoelectrical techniques to evaluate the flaky graphite reserves found along the east coast of Madagascar. The high conductivity of graphite makes it detectable using electrical resistivity tomography, induced polarization, and electromagnetic methods. Abdullahi et al. [10] implemented the electric resistivity tomography (ERT) method to remap the gold deposits scattered in Bugai Village Birnin, Gwari Local Government Area of Kaduna State, Nigeria. Also Ramazi and Mostafaie [11] employed various geoelectric methods such as resistivity, IP, and self-potential (SP) in manganese ore detection in the Marand area in Iran.

\subsection{Geologic settings and mineralogy}

An approximately $95 \mathrm{~km}^{2}$ area in Korab-Kansi contains titanomagnetite ore and is bounded by $22^{\circ} 31^{\prime} 06^{\prime \prime} .4$ and $22^{\circ} 38^{\prime} 46^{\prime \prime} .4 \mathrm{~N}$ latitude and $34^{\circ} 58^{\prime} 35^{\prime \prime} .86$ and $35^{\circ} 02^{\prime}$ $47^{\prime \prime} .08 \mathrm{E}$ longitude (Fig. 1). Mafic and ultramafic rocks in the south Korab-Kansi area represent part of a largely concealed intrusion that intrudes into the Ophiolitic mélange of the area. Parts of this intrusion are encountered east and southeast of the study area. This intrusion is subjected to northwest-southeast compressing stress and dissected by different types of faults, resulting in modification of its original shape to the present-day feature. The rocks within the study area include a variety of mafic and ultramafic types but are dominated by the ultramafic type at the southern part of the area. The titanomagnetite ore occurrence is represented by a thin vertical layer within gabbroic rock. A simple geologic map constructed from the geologic map of Egypt after EGPC and CONCCO [12] is shown in Fig. 2a.

A petrochemical study of the layered gabbro and associated ultramafic rocks in the study area was carried out

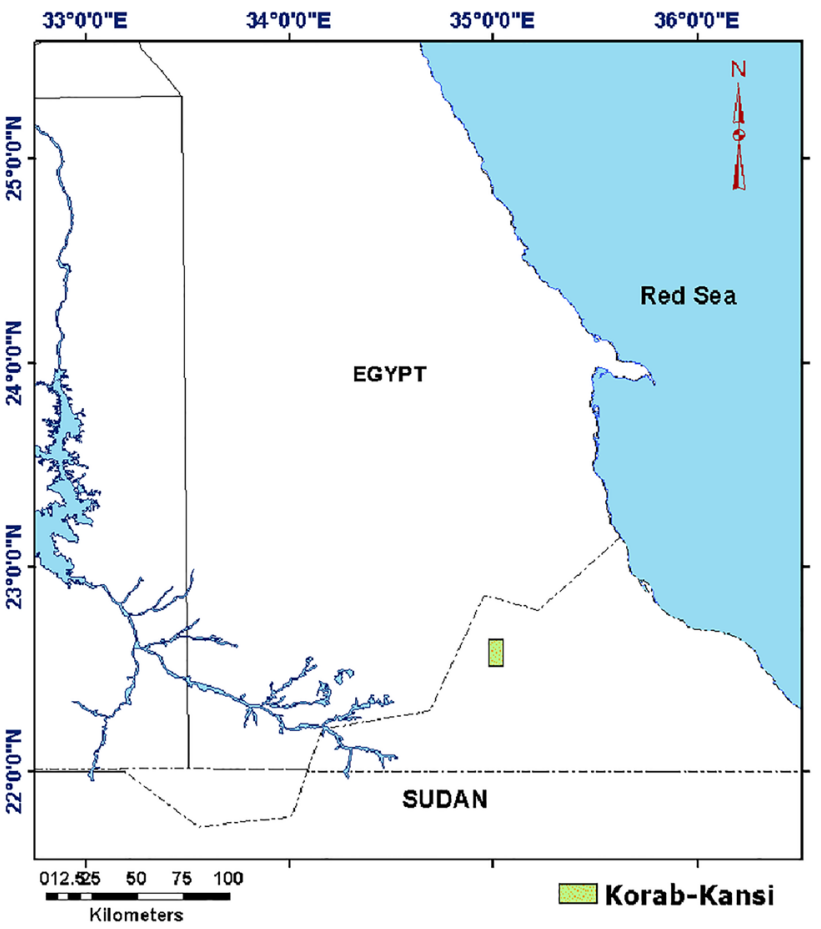

Fig. 1 Location map of the study area

on 27 wells by the Egyptian General Mineral Resource Authority (EMRA) [13]. The main result showed (1) the absence of hematite $(\mathrm{Hm})$, which is the nonmagnetic form of iron oxide. The average magnetite $(\mathrm{Mt})$ in all the studied rocks was $3.02 \%$ except in the iron-bearing dunite where it reached $18.22 \%$; (2) the average ilmenite (IL) in all the studied rocks was $1.26 \%$ except in iron-bearing dunite, where it was $16.3 \%$. All these ultrabasic rocks have a high magnetic signature; nonetheless, the high variation of the magnetic susceptibility between the ore and surrounding rocks makes it highly detectable.

\section{Data description}

Integrated geophysical methods (magnetic, vertical electrical sounding, and ERT surveys) were conducted in the study area. The geophysical survey was located above and around the exposed ore deposits. The location of all conducted geophysical work is shown in Fig. 2 b.

\subsection{Magnetic data}

The total magnetic survey was carried out along 47 parallel traverses in the west-east direction. This direction was selected because it is perpendicular to the titanomagnetite outcrops. All the magnetic measurements were carried out along the constructed traverses, and the line 


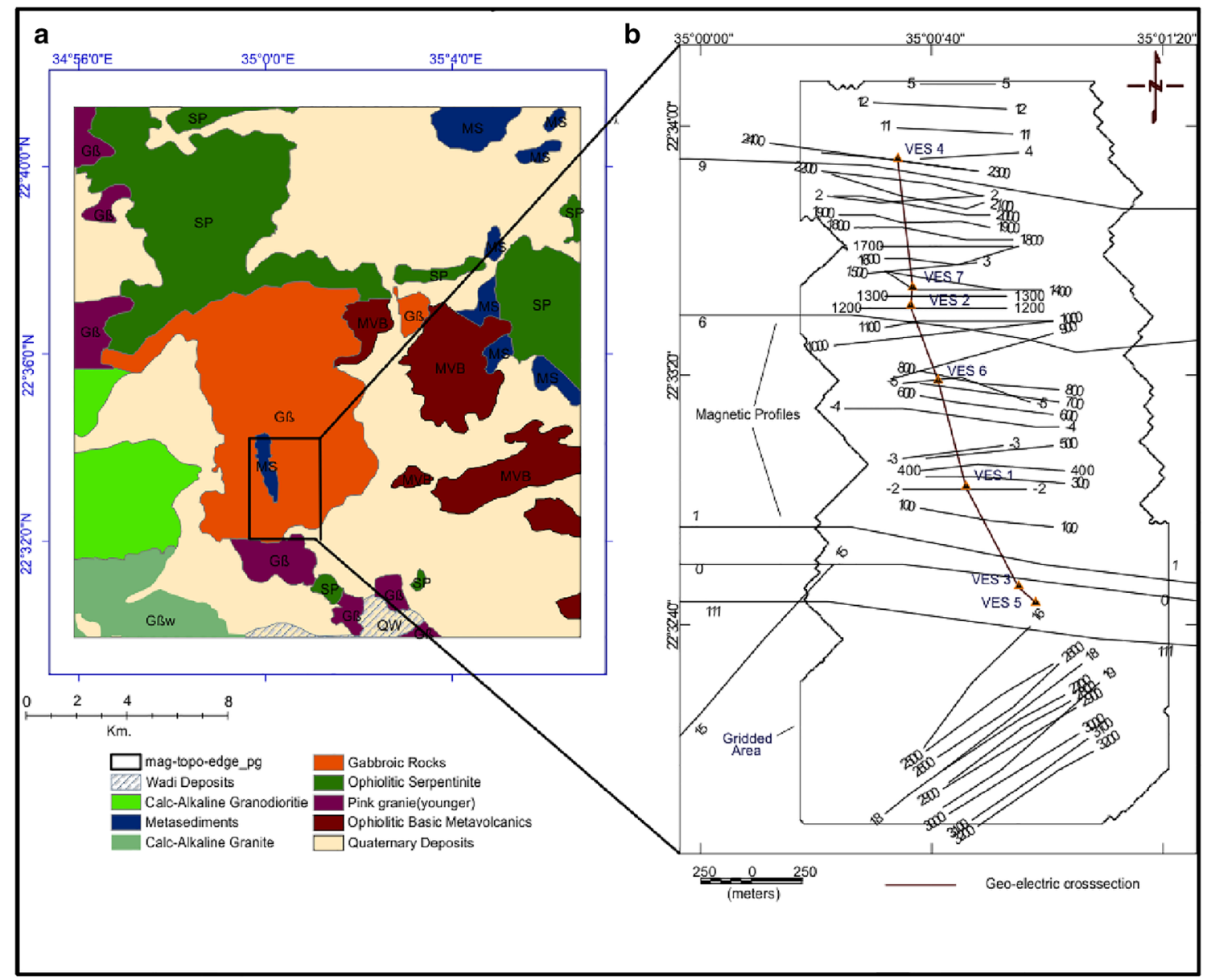

Fig. 2 a Geologic map of the study area contain the main lithological units, b location map of all the conducted geophysical survey, magnetic profiles, VES stations, ERT cross-section's, the Resistivity

separations in the survey ranged between 50 and $200 \mathrm{~m}$. The station separations were $10 \mathrm{~m}, 5 \mathrm{~m}$, and $2 \mathrm{~m}$ to detect the locations and trends of the titanomagnetite mineralization zones. A Geometrix Digital Proton Magnetometer (type $816 \mathrm{G}$ ) of 1 nanoTesla (nT) accuracy was used in this survey. A Proton Precision Magnetometer was used as a base station.

\subsection{Geoelectrical data}

Seven vertical electrical soundings (VES) were made to cover the study area to detect the maximum depth of the conductive zones, and the location of each VES was selected depending on field observation of the titanomagnetite ore outcrops. In addition to three ERTs, cross sections were made trending east-west perpendicular to the direction of the exposed ore in the area. The measurements were completed using IRIS resistivity and an ELRECT induced polarization (IP) system.
Profile, and the polygon delineate the gridded magnetic data used in further qualitative interpretation

The vertical electrical sounding is measured using the Schlumberger array. The maximum current electrode spacing $(A B)$ chosen was $1000 \mathrm{~m}$ at most of the soundings aiming to obtain sufficient information about the thickness (h) and electric resistivities ( $\rho$ ) of the different depths. Typically, less than one-fifth of the spacing between the current electrodes was achieved. The current electrodes were increased to a greater separation during the survey while the potential electrodes remained in the same position. Usually, the apparent resistivity $\rho_{\mathrm{a}}$ is computed using Eq. (1).

$\rho_{\mathrm{a}}=\frac{\pi a^{2}}{b}\left(1-\frac{b^{2}}{4 a^{2}}\right) \frac{\delta V}{l}$

where $a$ is the spacing between the potential electrodes, $b$ is the spacing between the current electrodes, $V$ is the voltage in millivolts, and $l$ is the current in milliamperes.

The dipole-dipole array is used to measure the ERT resistivity pseudo-sections and the IP; the IP data are 
measured in the time domain where the current is sent into the ground through stainless steel electrodes for a definite period ( $2000 \mathrm{~ms}$ ). Then, the current is automatically turned off, and the voltage between potential electrodes is automatically recorded. The global chargeability $(M)$ is automatically calculated according to the average of four-time window of the partial chargeability in $\mathrm{mV} / \mathrm{V} \%$ or as an interval decay curve in milliseconds.

\section{Data interpretation}

\subsection{Magnetic data interpretation}

The total magnetic intensity map is shown in Fig. 3a. The magnitude of the anomalies ranged from $37,071.2$ to $42,130 \mathrm{nT}$. In the reduced pole (RTP) map after the removal of the International Geomagnetic Reference Field (IGRF) model with the following parameters, the field strength is $40,087 \mathrm{nT}$, inclination $31.4^{\circ}$ and declination $2.7^{\circ}$; the RTP map is shown in Fig. 3b. The magnitude of magnetic anomalies in the RTP map ranges from -3707 to $4319 \mathrm{nT}$, and the anomalies spread mostly in the west and middle of the measured area with northeast-southwest direction. We can also see the distribution of the maximum amplitudes concentrated in the south, middle, and northern part and the high magnitude related to the high magnetic susceptibility of the titanomagnetite. All the processing of magnetic data is carried out using Geosoft Oasis Montaje [14].

\subsubsection{Total horizontal gradient and analytic signal}

The analytic signal and total horizontal gradient (THG) are the best filters to detect the magnetic source location. The analytic signal calculated using the Hilbert transformation can identify the positive and negative parts related to the same anomaly; the magnitude of the analytic signal ranges from 1 to $180 \mathrm{nT} / \mathrm{m}$. The analytic signal is shown in Fig. 3c. The amplitude analytic signal filter of the total magnetic field $\mathrm{H}$ is calculated from the three orthogonal derivatives of the field using Eq. (2) of Roest et al. [15]:

Analytic Signal $=\sqrt{\left(\frac{\delta H}{\delta x}\right)^{2}+\left(\frac{\delta H}{\delta y}\right)^{2}+\left(\frac{\delta H}{\delta z}\right)^{2}}$

The THG in both horizontal directions is related to the vertical direction. These filters are not distressed by the bipolarity of the magnetic field. The THG was estimated by Phillips [16]. The amplitude of the horizontal gradient according to Cordell and Grauch [17] is expressed as Eq. (3)
Horozontal gradient $=\sqrt{\left(\frac{\delta H}{\delta x}\right)^{2}+\left(\frac{\delta H}{\delta y}\right)^{2}}$

where $H$ is the magnetic field intensity.

The THG is shown in Fig. 3d. The magnitude of the THG ranges from 1 to $168.9 \mathrm{nT} / \mathrm{m}$. A plot of the main segments of titanomagnetite layers as detected from the field observation is shown in the figure, where the high gradient zones are located parallel to the observed ore segments.

\subsubsection{Depth estimation using 2D magnetic inversion}

In this method, interpretations of magnetic anomalies are made by assuming that the measured magnetic fields are related to a rectangular magnetized body, with flat-topped and infinite depth, or in the short term as vertical prisms. A prism is assumed to be a simply shaped magnetic source. The depth to the top surface and the dimension of the magnetized body are calculated using Geosoft Oasis Montaj; the program can calculate the parameters of an inductively magnetized body of simple geometry like in tabular 1 and 2. A sample of the modeled magnetic anomaly is shown in Fig. $4 a-d$. The calculated parameters for some models are presented in Table 1.

The magnetic anomalies in the total intensity profiles were modeled assuming the field strength was 40,087 nT, inclination $31.4^{\circ}$, and declination $2.7^{\circ}$. About 95 anomalies were processed for depth estimation. The depth of the simple shape tabular one sources ranged from 1.54 to $44.55 \mathrm{~m}$. Magnetic susceptibility ranged from 0.0037 to 0.514 CGS units, and the misfit ranged from 0.021 to $0.2 \%$. For the depth of the simple shape tabular 2, two sources ranged from 3.05 to $50.1 \mathrm{~m}$. Magnetic susceptibility ranged from 0.0034 to 0.611 CGS units, and the misfit ranged from 0.038 to $0.3 \%$. The depth of simple magnetic step sources ranged from 1.48 to $37.34 \mathrm{~m}$. Magnetic susceptibility ranged from 0.0082 to 0.625 CGS units, and the misfit ranged from 0.049 to $0.21 \%$.

The depth of the magnetic source (assumed to be the ore body) appeared to range from 1 to $50.1 \mathrm{~m}$. The source's depth to the top map was constructed and is shown in Fig. 5a. We should point to some anomalies with exaggerated thickness. The susceptibility was removed from the table and the map. The calculated thickness plots are shown in Fig. $5 \mathrm{~b}$ where the calculated thickness ranged from 7 to $100 \mathrm{~m}$. The area was divided into two zones of maximum thickness in the northern and southern parts; both areas extend north-south as described in the figures. 
Fig. 3 a The total magnetic intensity map; $\mathbf{b}$ the reduced pole map; $\boldsymbol{c}$ the analytical signal map; $\mathbf{d}$ the total horizontal gradient map
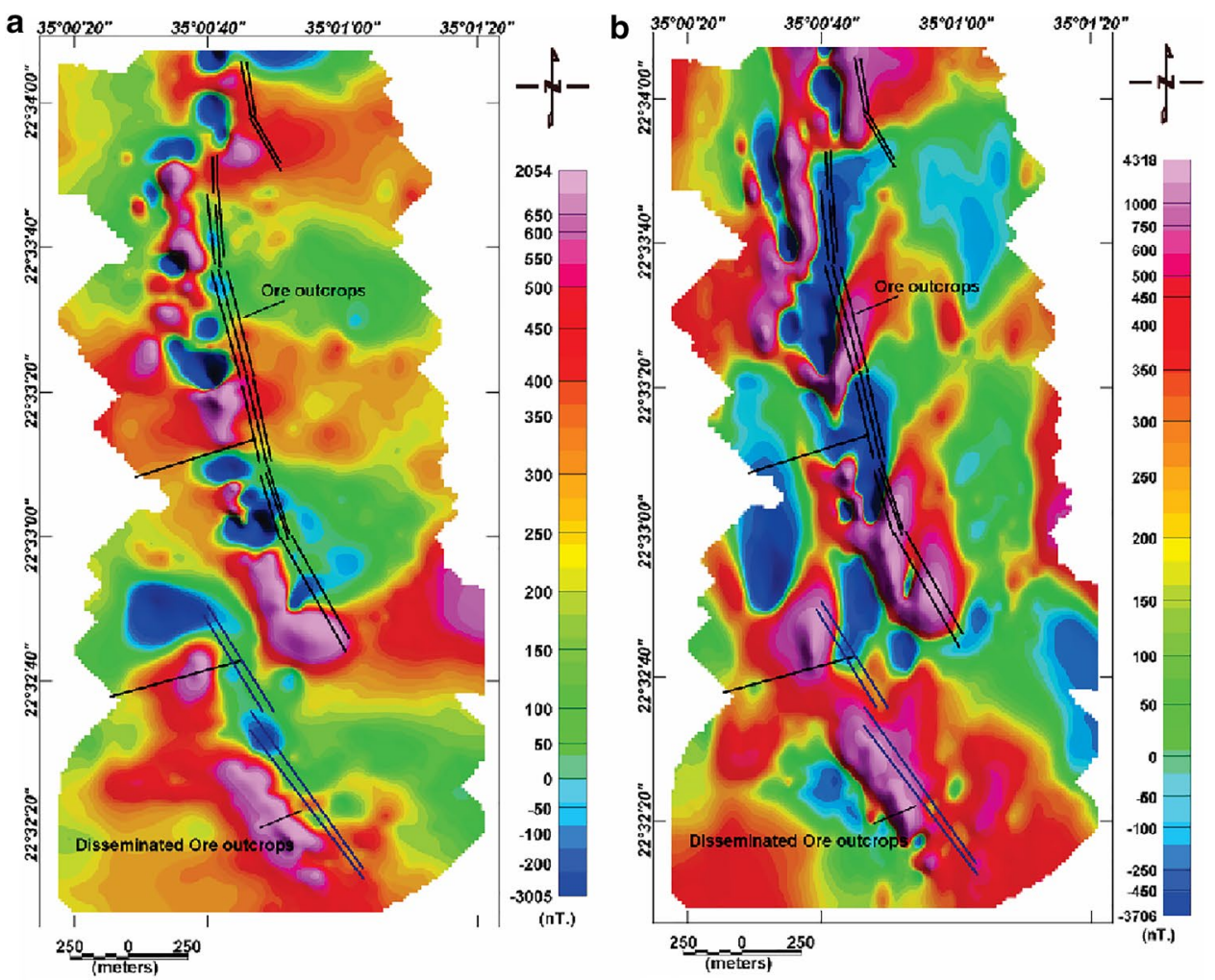

C
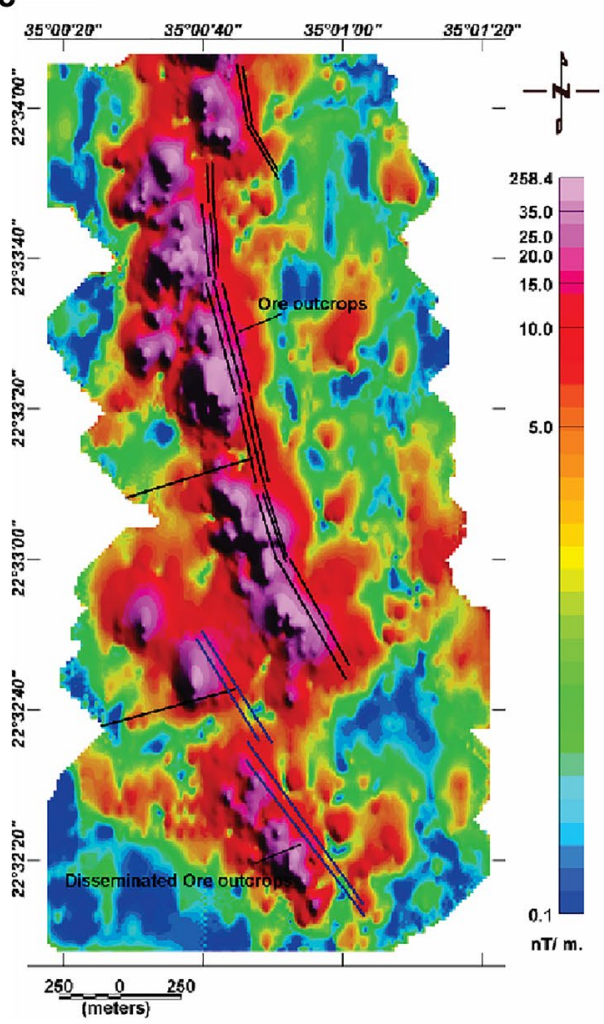

d

$35^{\circ} 00^{\prime} 20^{\prime \prime} \quad 35^{\circ} 00^{\prime} 40^{\prime \prime} \quad 35^{\circ} 0100^{\prime \prime} \quad 35^{\circ} 01^{\prime 2} 20^{\prime \prime}$

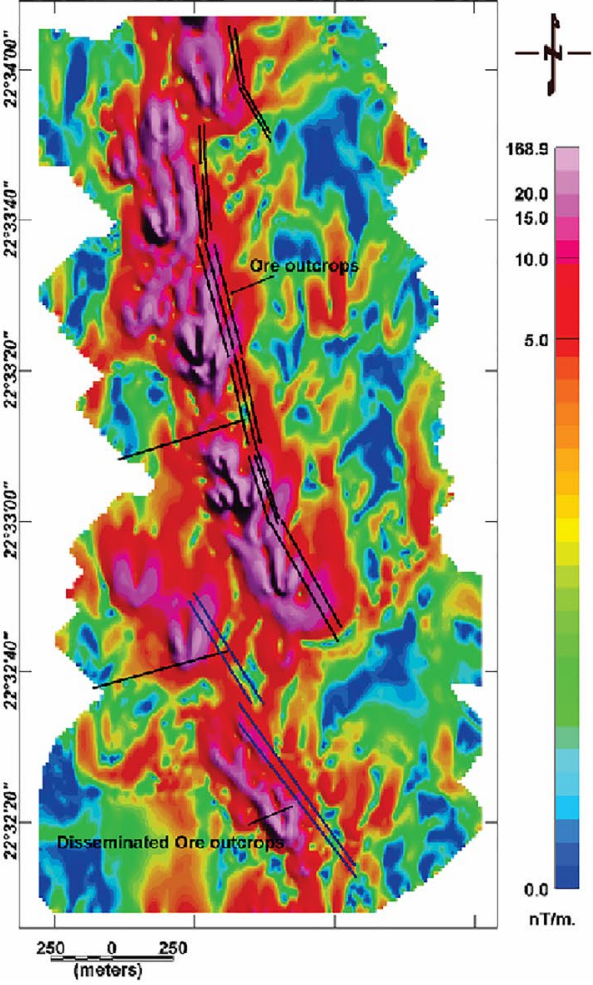



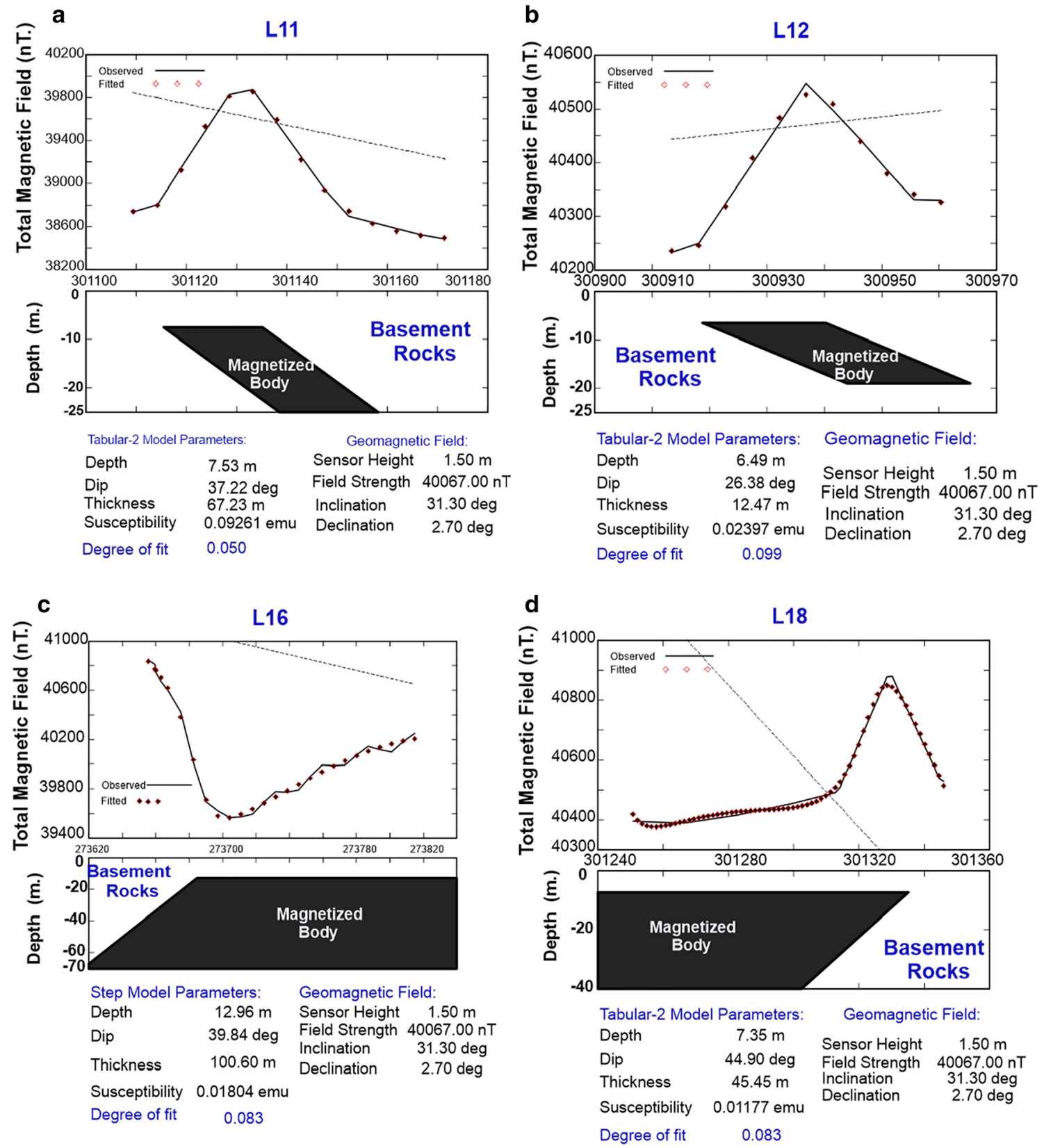

Fig. 4 Selected anomaly samples of the inverted magnetic results (a-d) are anomalies from profiles L11, L12, L16, and L18, respectively

\subsection{Interpretation of vertical electrical sounding data}

The processing of vertical electrical sounding data was completed by the Ix1d v.3.5 [18] program. We used an initial model for each VES. The inversion process matched a resistivity curve with the initial model. The initial model with constructed using master curve matching method after Orellana and Mooney [19]. The theoretical background of the program was constructed according to Anderson [20], Bostick [21], Constable et al. [22],
Degroot-Hedlin and Constable [23], and McNeill [24]. All models are shown in Fig. 6a-g.

The geoelectric VES curve obtained from the interpretation of these VES curves showed that all curves were divided into three resistivity zones. The geoelectric resistivity (VES) interpretation results showed that the total thickness of the titanomagnetite ore ranged between $48.7 \mathrm{~m}$ and $80 \mathrm{~m}$ in the three segments. These resistivity results strongly supported the geomagnetic modeling results and were used to build the geologic section that describes the titanomagnetite ore deposits in the study area. 
Table 1 Results of some calculated magnetic anomalies

\begin{tabular}{llllllcccc}
\hline Line no. & Anomaly ID & Model type & $\begin{array}{l}\text { Misfit } \\
\%\end{array}$ & $\begin{array}{l}\text { X } \\
\text { UTM }\end{array}$ & $\begin{array}{l}\text { Y } \\
\text { UTM }\end{array}$ & $\begin{array}{l}\text { Depth } \\
(\mathrm{m})\end{array}$ & $\begin{array}{l}\text { Thickness } \\
(\mathrm{m})\end{array}$ & \begin{tabular}{l} 
Susceptibility \\
\cline { 6 - 8 }
\end{tabular} \\
& & & & & & & & SI units \\
\hline 100 & A_45 & Step & 0.105 & $301,360.8$ & $274,501.9$ & 3.04 & 29.115 & 0.31651 \\
1000 & A_62 & Tabular2 & 0.108 & $300,919.9$ & $275,383.1$ & 13.92 & 40.334 & 0.20022 & 2.515 \\
1000 & A_63 & Tabular2 & 0.076 & $301,635.9$ & $275,462.1$ & 25.7 & 34.47 & 0.03966 & 0.498 \\
11 & A_30 & Tabular2 & 0.081 & $301,125.3$ & $276,419.5$ & 7.53 & 67.227 & 0.09261 & 1.163 \\
11 & A_31 & Tabular1 & 0.235 & 301,447 & $276,402.3$ & 20.92 & & 0.01917 & 0.240 \\
1100 & A_66 & Step & 0.236 & $301,114.2$ & $275,474.1$ & 17.92 & 68.009 & 0.62497 & 7.853 \\
12 & A_33 & Tabular1 & 0.099 & $301,030.8$ & $276,542.6$ & 15.94 & & 0.11977 & 1.505 \\
1200 & A_67 & Tabular2 & 0.067 & 300,995 & 275,536 & 9.87 & 84.007 & 0.05569 & 0.699 \\
\hline
\end{tabular}

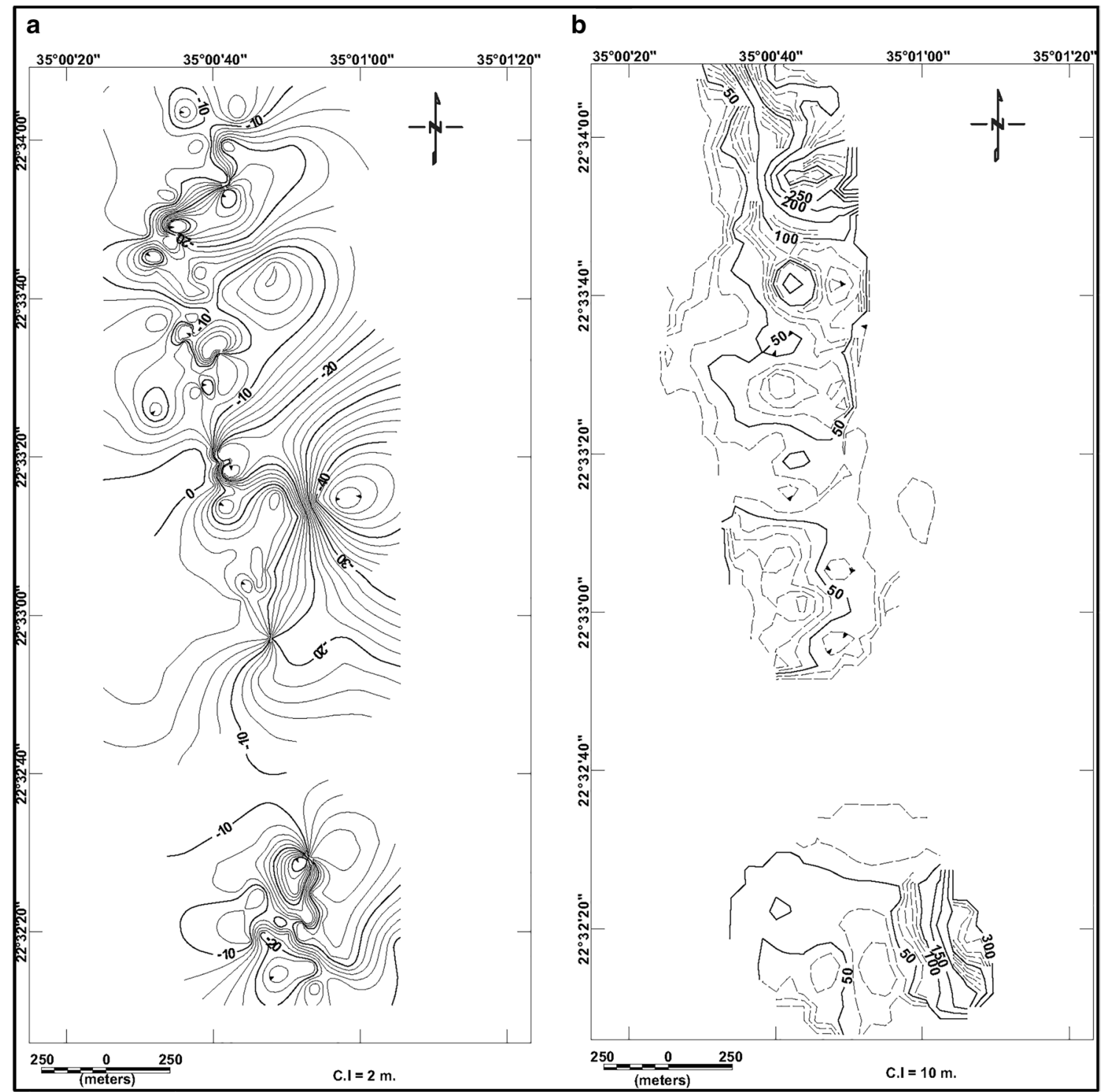

Fig. 5 a Simple contour map of the depth of magnetic sources. b Average thickness of detected magnetic sources 

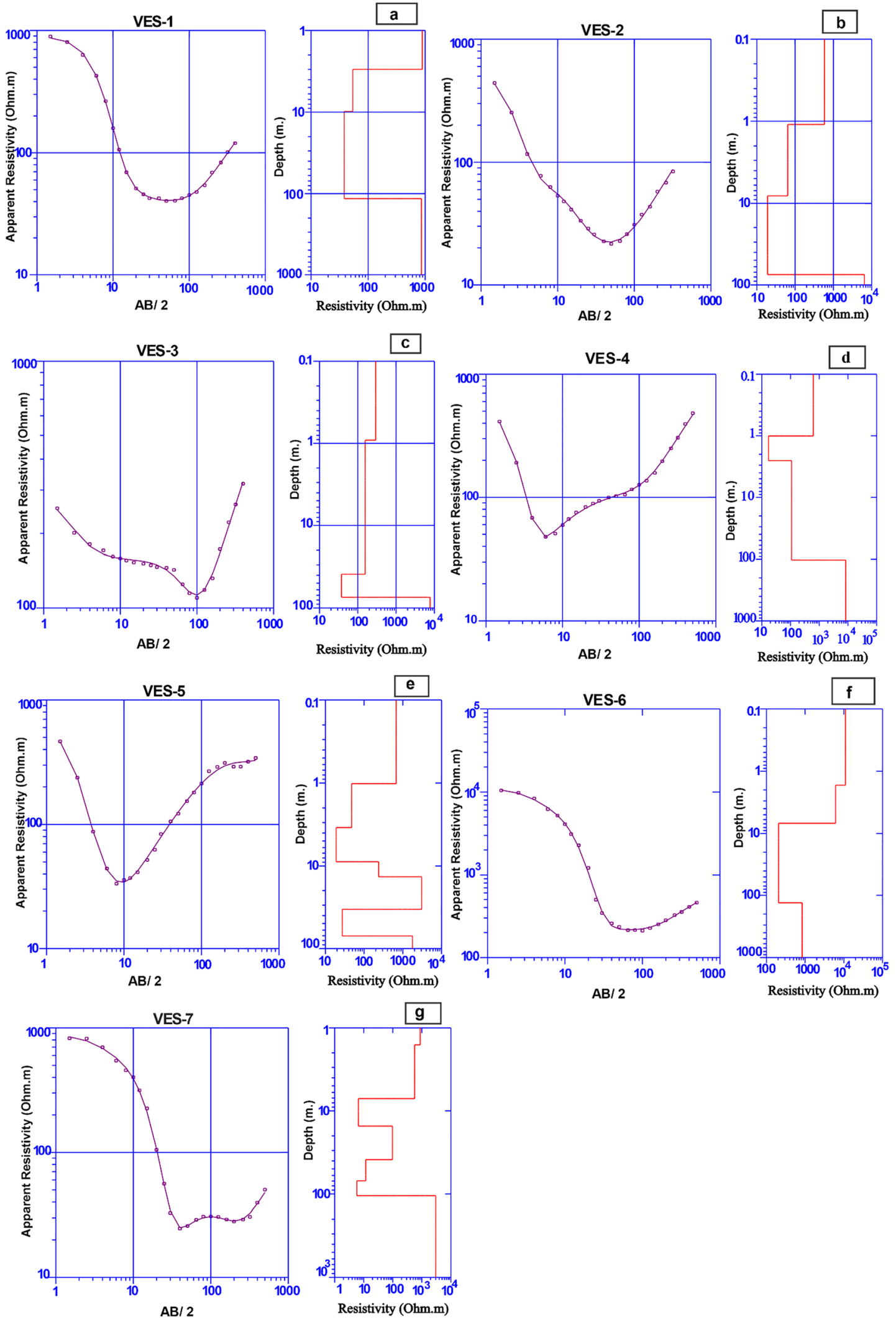

Fig. 6 a-d Models of vertical electrical sounding nos. 1, 2, 3, and 4, respectively. e-g Models of vertical electrical sounding nos. 5, 6, and 7, respectively 
The first resistivity segment was relatively high and related to the titanomagnetite surface layer. The first meter showed high resistivity due to the lake of moisture of the weathered zone and depth range from 0.9 to $3.0 \mathrm{~m}$. The second segment had a low resistivity value and was related to the massive titanomagnetite zone. The third resistivity curve segment had a high resistivity value and was related to the host gabbroic rocks beneath the titanomagnetite ore zone. Some VESs showed more than three segments, for example, VES-5, where there is intercalation between the low-resistivity ore body and the high resistivity host rock. The titanomagnetite ore had a resistivity value ranging between 6 and $206 \Omega \mathrm{m}$. This wide range was related to the form of the ore body and the concentration of the titanomagnetite mineral and its association with the host rock.

The modeled VES data can be gathered in cross section because all of the VES had an east-west orientation, and most had a common centerline trending northsouth. A cross section trending north-south was modeled using all seven VESs included in our study generated by the Ix $1 \mathrm{~d}$ v3.5 shown in the Fig. 7a. A geologic cross section was constructed by the correlation between all the VES models shown in Fig. 7b. The inversion was applied to the seven VES curves to generate a $2 D$ resistivity model. In this case, the inversion algorithm considered the lateral variation of resistivity calculated from each VES relative to the horizontal distance between each VES. In the cross sections below, we can see two main low resistivity units representing the titanomagnetite zone in the first zone located to the north under the location of the $\operatorname{VES}(5,3$, and 1$)$; the other was in the south under the VES $(2,7$, and 4$)$. The results of all geoelectric VES models are represented in the Table 2.
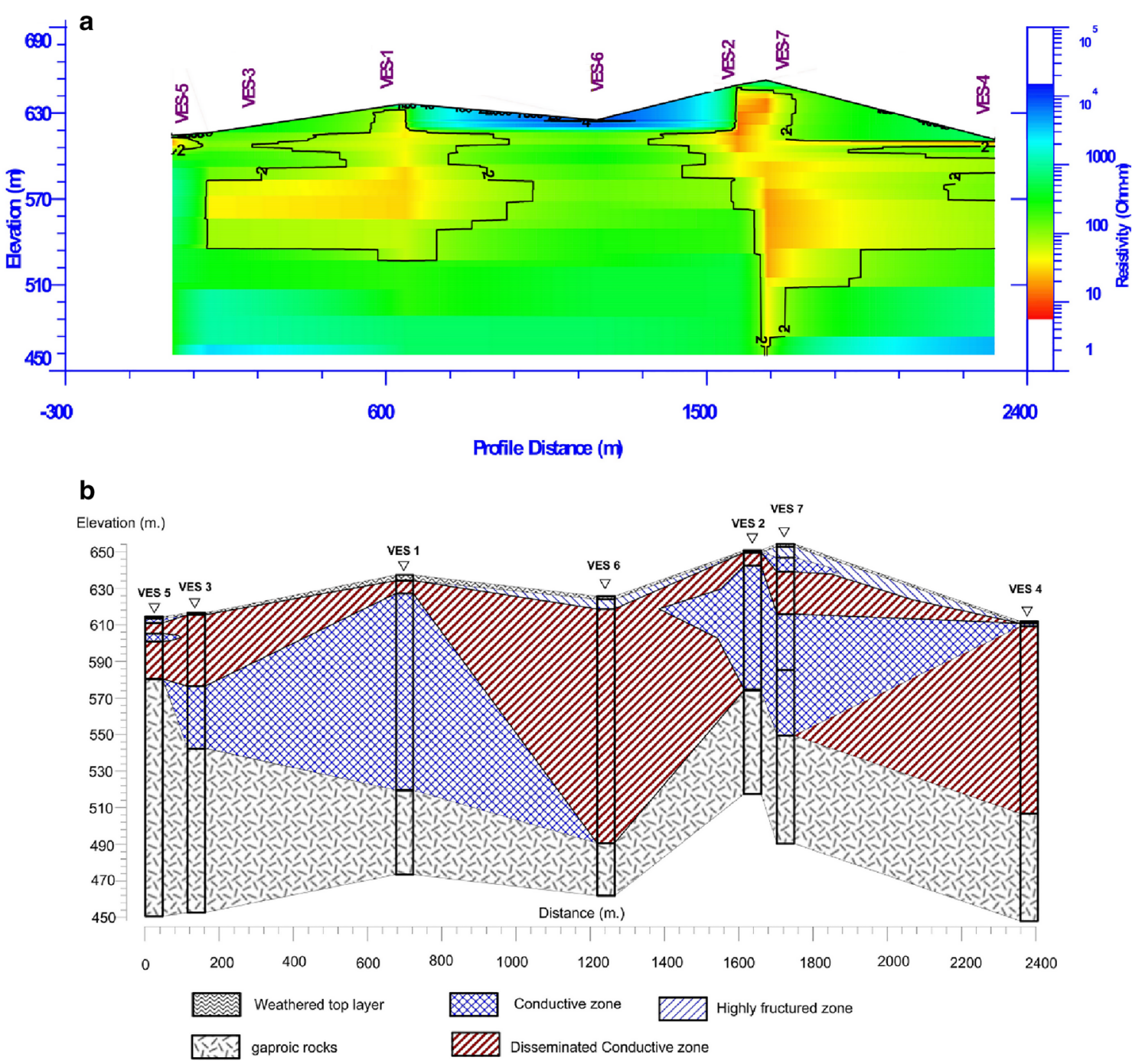

Fig. 7 a A 2D model of the inverted cross section using all VES. b Geologic section constructed by geologic correlation of all VES models 
Table 2 Depths and resistivity of the low-resistivity zone as summarized according to the geoelectric method

\begin{tabular}{llll}
\hline VES no. & $\begin{array}{l}\text { No. of resistivity } \\
\text { layers }\end{array}$ & $\begin{array}{l}\text { Ore resistivity } \\
\text { range }(\Omega \mathrm{m})\end{array}$ & $\begin{array}{l}\text { Maximum ore } \\
\text { thickness }(\mathrm{m})\end{array}$ \\
\hline 1 & 4 & $38: 54$ & 112 \\
2 & 4 & $19: 64$ & 73.6 \\
3 & 4 & $36: 156$ & 71 \\
4 & 4 & $17: 109$ & 101.5 \\
5 & 7 & $34: 276$ & 48.7 \\
6 & 4 & 206 & 125.2 \\
7 & 7 & $6: 101$ & 95.2 \\
\hline
\end{tabular}

\subsection{Interpretation of the ERT cross section}

Two electrical imaging methods, ERT and IP, were chosen for this study. The ERT method was used to distinguish the ore bodies from the surrounding rocks by using the resistivity value contrast whereas the IP method was used to differentiate between massive and disseminated ore by differentiating the charge ability values of the subsurface materials. Three ERT lines were made trending east-west perpendicular to the direction of revealed ore in the area. The location of these lines is shown in Fig. $2 b$.

Cross-section no. 1 is shown in Fig. 8a. The resistivity model was shown with the topography; the profile length was $315 \mathrm{~m}$. The reach depth was about $46 \mathrm{~m}$. The resistivity value of the model ranged from 0 to $21,500 \Omega \mathrm{m}$. The resistivity distribution indicated a low resistivity body that is likely to be the titanomagnetite ore body. The smallest resistivity part was probably related to the water-saturated zone. The highest resistivity value was related to the host rock, which was a massive gabbroic rock unit. The profile center was carried on top of the titanomagnetite ore outcrop.

Cross section no. 2 in Fig. 8b showed the resistivity, and the IP models were shown without the topography assuming the profile along the earth surface. The profile length was $315 \mathrm{~m}$. The reach depth was about $46 \mathrm{~m}$. The resistivity distribution indicated a low resistivity main body that was probably titanomagnetite ore. The smallest resistivity part was probably related to the water-saturated zone. The highest resistivity value was related to the host rock, which was a massive gabbroic rock. This conclusion can be correlated with the IP model from the chargeability values. We could detect two main ore bodies and several disseminated small lenses.

Cross section no. 3 is shown in Fig. $8 c$. The profile length was $315 \mathrm{~m}$, and the reach maximum depth was about $46 \mathrm{~m}$. The visual inspection showed that the resistivity distribution indicated a low resistivity main body that was probably a titanomagnetite ore body. A water-saturated zone was also present. The highest resistivity value was related to the host rock, which was a massive gabbroic rock unit. The chargeability values indicated the main ore body and several disseminated small lenses with high chargeability values.

The interpretation of the inverted models of the three sections of dipole-dipole resistivity and chargeability can be summarized as follows. The low resistivity zones that are enclosed with a high charge ability value can be considered an indicator of enrichment with massive titanomagnetite deposits, but disseminated titanomagnetite deposits give high resistivity values and weak to moderate chargeability. The inverted models show two forms of conductive bodies. The most abundant form is dike shaped. This result agrees with the magnetic depth estimation. The second form is isolated small lenses of the highly conductive body.

\subsection{Integrated interpretation of magnetic and geoelectric data}

The results obtained from magnetic qualitative and quantitative analysis with the results from vertical electrical sounding inversion are summarized in a simple location map of the assumed titanomagnetite ore bodies in Fig. 9. Also, the main results of the two techniques are shown in Table 1. As we can see, the two methods agreed in detecting the probable titanomagnetite ore body as delineated by area (A). Also a second area B was delineated only according to the magnetic method depending on the high magnetization ore units delineated by area (B).

\section{Discussion}

The main aims of this research were (1) to study the physical response of a high-contrast earth model by different geophysical prospecting methods and (2) to detect the vertical and horizontal distribution of titanomagnetite in the studied area. The observed geophysical model can be assumed depending on the geologic setting of the ore, which describes it as a vertical body with high magnetic susceptibility and low resistivity surrounded by basement rocks with low magnetization and high resistivity.

All the geophysical methods detect sources of high magnetic susceptibility and low resistivity in the same form that was described by the geology. The depth obtained with a 2D magnetic modeling method was < 10 meters below the ground surface. Most modeled magnetized bodies are in the shape of a dike (tabular). Also, the $2 \mathrm{D}$ resistivity and chargeability can be summed up as follows. The low resistivity zones enclosed the high chargeability value, which might be considered an indicator of 

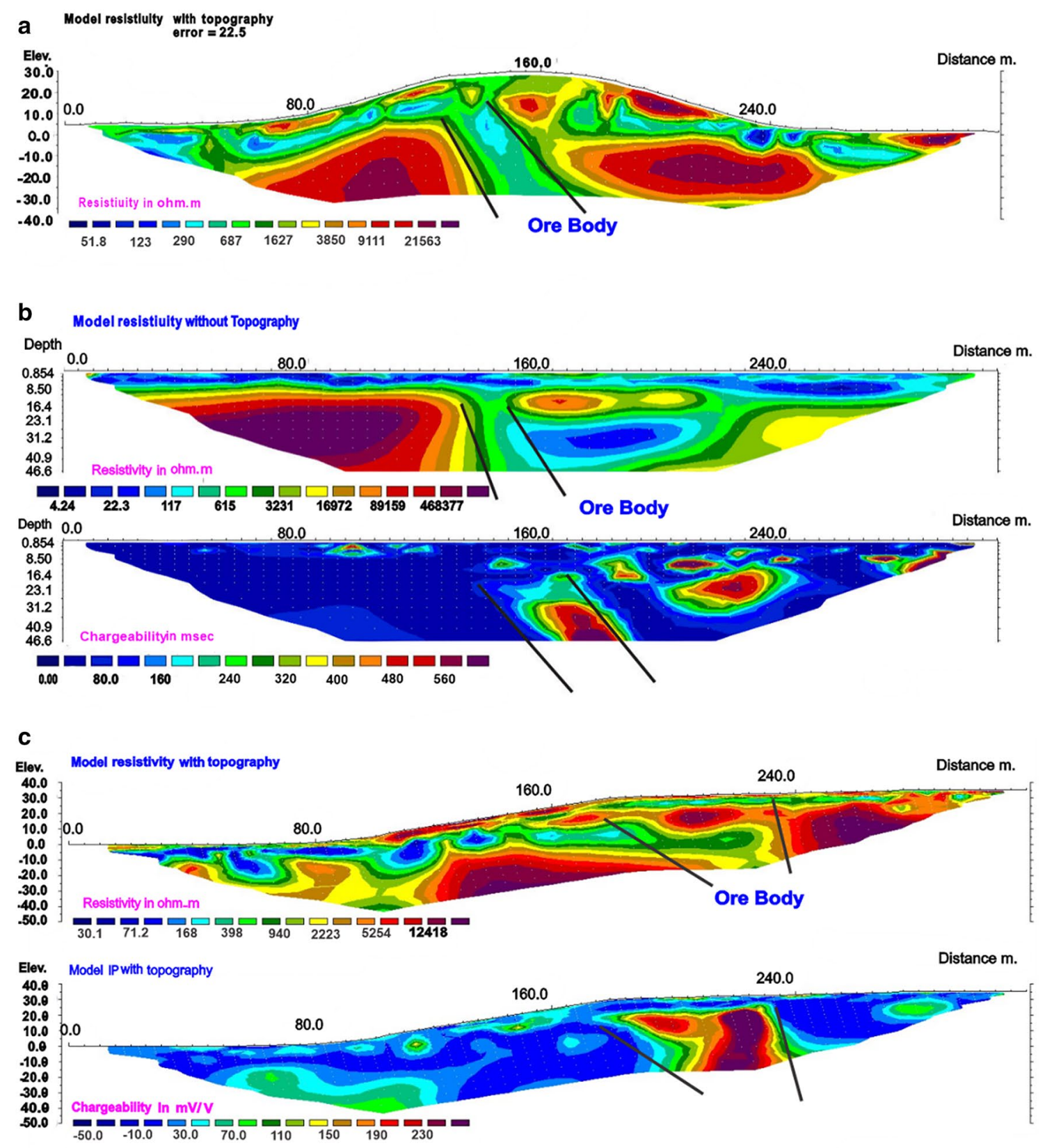

Fig. 8 a Resistivity model measured at profile one. $\mathbf{b}$ and c ERT profiles two and three. All the lower resistivity and higher chargeability are delineated and defined as the titanomagnetite ore and delineated by lines

enrichment with massive titanomagnetite deposits, but disseminated titanomagnetite deposits give high resistivity values and weak to moderate chargeability. We can describe two forms of conductive bodies in the area. The most abundant form is dike shaped; the second form is isolated small lenses of highly conductive bodies. These two methods indicate the same shape and geometry of the metallic ore.
From the quantitative and depth analyses, the results of magnetic quantitative interpretation detected different magnetic bodies of tabular shape at depth $<10 \mathrm{~m}$, and their thickness ranged from 29.1 to $84 \mathrm{~m}$. The results of geoelectric sounding inversion detect two zones of lowresistivity values $<100 \Omega \mathrm{m}$, and thickness ranged from 48.7 to $80 \mathrm{~m}$. The similarity between the results proved the first idea. 


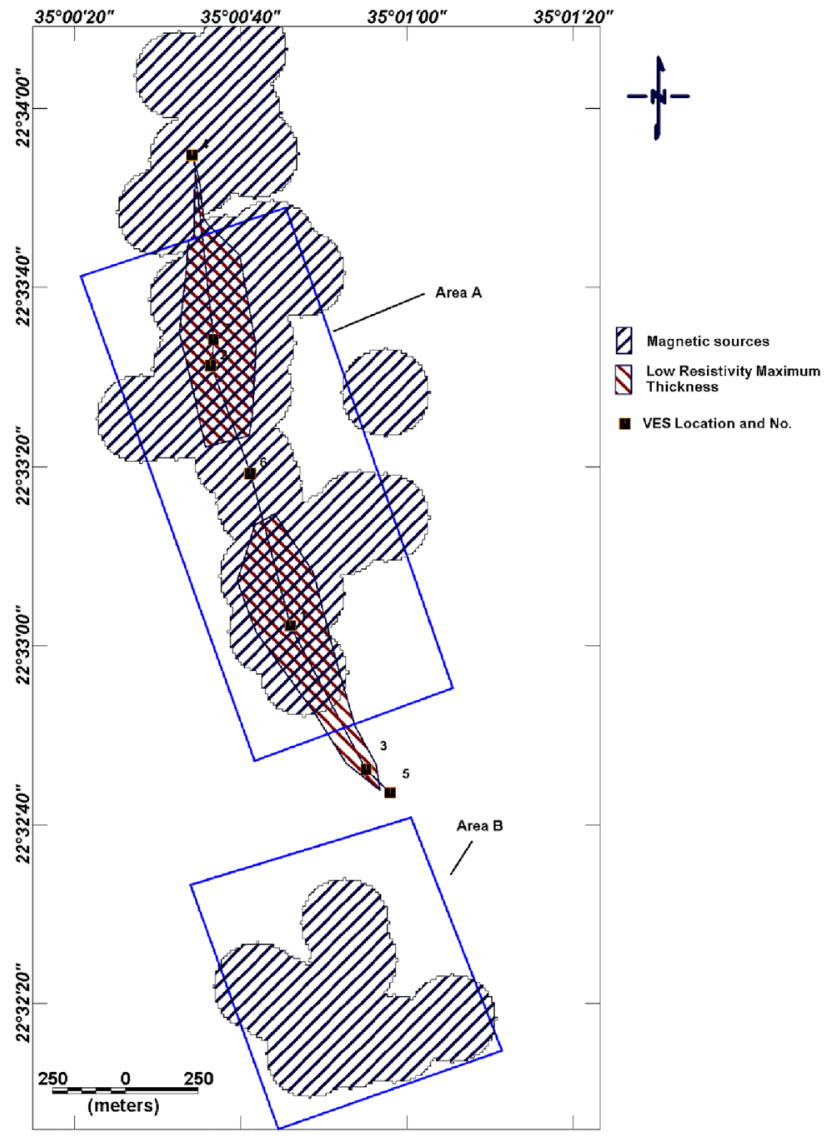

Fig. 9 Integrated map between the magnetic and vertical electric sounding results showing the area of ore potential

The horizontal distribution of the titanomagnetite ore is shown by the results of magnetic qualitative interpretation. There are four parallel, elongated, highly magnetized zones extending north-south, as shown by the total horizontal gradient and analytic signal maps (Fig. 3c, d). Also, for the vertical electrical sounding models, there are two zones of low resistivity with vertical orientation, and the horizontal distribution matches the elongated anomalies from the magnetic method. The first zone is located within the spatial location at VES nos. 5, 3, and 1 with maximum thickness up to $60 \mathrm{~m}$. The second zone within the spatial location of VES no. 2, 4, and 7 with maximum depth of about $80 \mathrm{~m}$ is represented in Figs. 7 and 9 . All the results indicate the presence of the ore in the area and its extension horizontally and vertically. The magnetic and geoelectric methods are successfully employed in this research to evaluate metallic ores, similar to the previous work published by Heritiana et al. [9], Anaïs et al. [8], and Abdullahi et al. [10], after all the aims of the study had been satisfied.

\section{Conclusions}

(1) Magnetic and geoelectrical methods were successfully applied to detect mineralization of titanomagnetite in the Korab-Kansi area. (2) The geologic setting of metallic ore defines its occurrence as small thin vertical layers within the gabbroic host rock. (3) Qualitative magnetic analysis and modeling of the separated magnetic anomaly indicate the same shape of the mineral. (4) The ERT method shows more of the same shape of the ore at $<100 \Omega \mathrm{m}$. (5) To give a general idea about the conductivity in the area, VES analysis shows very thick and highly conductive zones; this research proves that the advancement of geophysics in data acquisitions, processing, and interpretation can be a great asset in the area of mineral exploration, in addition to other exploration methods. The key is to find the appropriate physical tool for them. In this research, the presence of magnetite minerals in the ore gives an advantage to the exploratory approach using magnetic and electric exploration methods.

Acknowledgements The authors thank the team who helped the authors collect the measured data, the Egyptian Mineral Resources Authority (EMRA), Cairo, Egypt.

\section{Compliance with ethical standards}

Conflict of interest The authors declare that there is no conflict of interest.

\section{References}

1. Clark DA, Emerson DW (1991) Notes on rock magnetization characteristics in applied geophysical studies. Explor Geophys 22:547-555

2. Takla MA (1971) Ore mineralogical and geochemical studies of some basic and associating ultrabasic igneous rocks. Eastern Desert, Egypt. PhD thesis, Cairo University

3. Takla MA, Basta EZ, Fawzi E (1981) Characterization of older and younger gabbros of Egypt. Delta J Sci 5:279-314

4. Zimmer M, Kroner A, Jochum KP, Reischmann T, Todt W (1995) The Gabal Gerf complex: a Precambrian N-MORB ophiolite in the Nubian-shield, NE Africa. Chem Geol 123:29-51

5. Brabers VAM (1995) The electrical conduction of titanomagnetites. Phys B Condens Matter 205(2):143-152

6. Radhakrishnamurty C, Likhite SD, Deutsch ER, Murthy GS (1982) On the complex magnetic behaviour of titanomagnetites. Phys Earth Planet Inter 30(4):281-290

7. Sultan SA, Mansour SA, Santos FM, Helaly AS (2009) Geophysical exploration for gold and associated minerals, case study: Wadi El Beida area, South Eastern Desert, Egypt. J Geophys Eng 6(2009):345-356. https://doi.org/10.1088/1742-2132/6/4/002

8. Brethes A, Guarnieri P, Rasmussen TM, Bauer TE (2018) Interpretation of aeromagnetic data in the Jameson Land Basin, central East Greenland: structures and related mineralized systems. Tectonophysics 724-725(2018):116-136 
9. Heritiana RA, Riva R, Ralay R, Boni R (2019) Evaluation of flake graphite ore using self-potential (SP), electrical resistivity tomography (ERT) and induced polarization (IP) methods in east coast of Madagascar. J Appl Geophys 169(2019):134-141

10. Abdullahi NK, Ahmad MS, Abubakar A (2018) Application of electrical resistivity tomography technique for delineation of gold mineralization in Bugai town, Birnin Gwari, Kaduna, North Western Nigeria. Environ Earth Sci Res J 5(1):29-35

11. Ramazi H, Mostafaie K (2013) Application of integrated geoelectrical methods in Marand (Iran) manganese deposit exploration. Arab J Geosci 2013(6):2961-2970

12. Egyptian General Petroleum Corporation (EGPC) and CONCCO (1987) Geological map of Egypt scale 1:500,000. South KorabKansi, sheet NF36 NE. Cairo, Egypt

13. Egyptian Mineral Resources Agency (2004) Internal report

14. Geosoft Oasis Montaje, V.8.2.4 (2015) Geosoft software for the earth sciences. Geosoft Inc., Toronto

15. Roest WR, Verhoef J, Pilkington M (1992) Magnetic interpretation using the 3-D analytic signal. Geophysics 57(1):116-125

16. Phillips JD (2000) Locating magnetic contacts: a comparison of the horizontal gradient, analytic signal, and local wavenumber methods. SEG 2000 expanded abstracts

17. Cordell L, Grauch VJS (1985) Mapping basement magnetization zones from aeromagnetic data in the San Juan Basin, New Mexico. In: Hinze WJ (ed) The utility of regional gravity and magnetic anomaly maps. Society of Exploration Geophysicists, Tulsa, pp 181-197
18. Ix1D V.3.5 (2011) Interpex Limited, P.O. Box 839, Golden, CO 80401, USA. www.interpex.com

19. Orellana E, Mooney HM (1966) Master take and curves for vertical electric sounding over layered structures. Interciencia, Madride, $34 \mathrm{pp}$

20. Anderson WL (1989) A hybrid fast Hankel transform algorithm for electromagnetic modeling. Geophysics 54:263-266

21. Bostick Jr FX (1977) A simple almost exact method of magnetotelluric analysis. In: Proceedings of workshop on electrical methods in geothermal exploration, U.S. Geological Survey, pp 174-183

22. Constable SC, Parker RL, Constable CG (1987) Occam's inversion: a practical algorithm for generating smooth models from EM sounding data. Geophysics 52:289-300

23. Degroot-Hedlin C, Constable S (1990) Occam's inversion to generate smooth, two-dimensional models form magnetotelluric data. Geophysics 55:1613-1624

24. McNeill JD (1980) Electromagnetic terrain conductivity measurement at low induction numbers. Geonics technical note TN-6, $15 \mathrm{pp}$

Publisher's Note Springer Nature remains neutral with regard to jurisdictional claims in published maps and institutional affiliations. 